\title{
DYNAMIC ANALYSIS AND SPEED CONTROL OF AC-DC ZETA CONVERTER FED DC MOTOR
}

\author{
A. M. El-Shebiny \\ South Delta Electricity \\ Distribution Company \\ Tanta, EGYPT
}

\author{
H. A. Yasin \\ S. S. Shokralla \\ Department of Electrical Engineering, \\ Faculty of Engineering, Minoufiya University, \\ Shebin El-Kom, EGYPT
}

\begin{abstract}
A simplified approach for speed control of a separately excited DC motor using single-phase, single-way rectifier is presented in this paper. The strategy of this approach is based on the cascade combination of a diode bridge rectifier and a Zeta converter. The power factor is near unity. The output voltage and current are smooth with ripple free. A high performance is achieved with a simple control circuit having only one switch for the converter. The analysis predicts the steady-state, run-up and dynamic behaviors of the proposed system in different modes of operation is presented. The IP controller parameters are selected from an overview of practical experience so that it satisfies the best required response for load and speed reference disturbances. Good agreement between experimental and simulated results has been observed, which supports the validity of the proposed analysis.

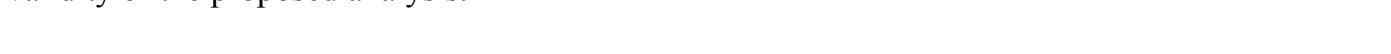

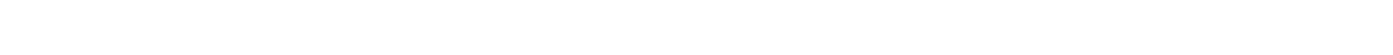

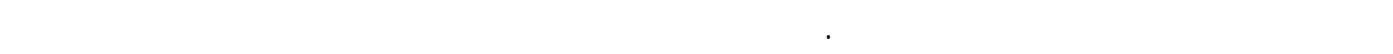

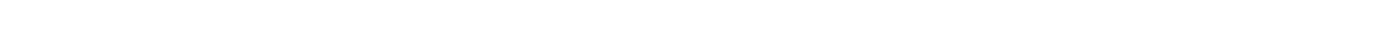

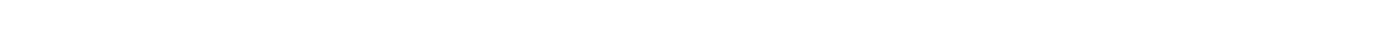

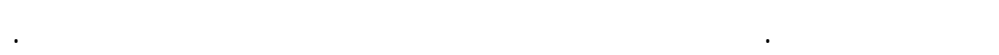

Keywords: Separately excited DC motor, Closed-loop speed control, AC-to-DC converter.

\section{INTRODUCTION}

The power supplies suffer from current distortion and low power factor operation. This is due to employing a conventional single-phase voltage source diode rectifier with a filter capacitor at the output terminal and also the phase controlled rectifiers using thyristors. In order to overcome these disadvantages, various circuit topologies using power switching devices, such as Gate Turn Off Thyristors, Power Transistors, MOSFET'S. and IGBT'S AC-to-DC converters have been implemented and obtain high power factor and minimum current distortion with static loads [1-7].

The advantages of using power electronic technology in electric device systems became doubtless fact, especially with the rapid and continuous increase in device ratings and speeds. However, power supplies of such systems suffer from current distortion and low power factor. These undesirable effects have motivated the international standard organization to impose restrictions on the magnitude of harmonic contents in the line currents of the switched mode power supplies. Although the problem of low power factor can be solved by adding power factor correction (PFC) equipments, such a solution may still be undesirable in terms of size, weight and cost [8].
Electronic power processing technology commonly is known as pulse-width modulation (PWM). The PWM technique processes power by controlling the duty cycle and interrupting the power flow, but results in pulsating voltage and current. Due to control easily and circuit simplicity, the PWM technique has been used predominantly in low power application. With circuit technologies, PWM converters have been designed to operate with a $30-50 \mathrm{KHz}$ switching frequency. In this frequency range, the equipment is deemed optimal in size, cost, efficiency, weight and reliability. Through this study, no attention has been paid to the transient performance of DC motor when supplied from the proposed converter [9-11].

In this paper, a simple AC-to-DC zeta converter feeding a separately excited DC motor is presented. This technique is performed without using a current sensor but only a simple control circuit with stepup/down capability is used. This converter yields an approximately unity power factor, in addition, the motor voltage and current are nearly ripple free.

The digital simulation for open and closed loop speed control system is given. The proposed experimental system is used to compute the best controller parameters for transient responses. Although the load was disturbed within the range $\pm 50 \%$ of its rated value, the motor speed appears to be consistent and 
remain constant. Also, the speed response due to a step change in the reference speed is fast with a reasonable overshoot. Finally, the simulation results are in good agreement when compared with the experimental values.

\section{DESCRIBTION OF THE EXPERIMENTAL SYSTEM}

Figure (1) shows the schematic diagram of the complete control system for speed control. The system consists of a cascade combination of a singlephase diode bridge rectifier and a zeta converter connected to AC single-phase supply. Step-up and step-down behavior of the output voltage is obtained by regulating the control voltage $\left(\mathrm{V}_{\mathrm{c}}\right)$ from 0 to maximum value $(A)$ of the timing voltage $\left(\mathrm{W}_{\mathrm{a}}\right)$ shown in Figure (2). This technique has been used to control the motor speed. Capacitor $C_{1}$ supplies energy to $L_{2}$. The capacitor $C_{2}$ is used as a DC filter to obtain smooth and ripple free output DC voltage.

The MOSFET is fired by an impulse generator having leaner timing voltage. The gate pulses are generated such that the control voltage $\left(\mathrm{V}_{\mathrm{c}}\right)$ equals the timing voltage $\left(\mathrm{W}_{\mathrm{a}}\right)$ as shown in Figure (2). Control of motor speed is performed using integral proportional (IP) controller. The switching frequency $\left(f_{s}\right)$ is set to 2 $\mathrm{KHz}$.

The parameters of the power circuit are determined according to the range of the switching frequency and acceptable percentage of the output ripple. The rate of change of $i_{1}$, switching frequency and value of $C_{1}$ are determined by the value of $\mathrm{L} 1$. The resonant frequency is given by $f_{r}=(1 / 2 \pi)\left(L_{1} C\right)^{0.5}$ and should be sufficiently lower than the switching frequency $\mathrm{f}_{\mathrm{s}}=1 / \mathrm{T}$ to prevent any resonant phenomenon in the AC circuit. The corner frequency of the low-pass filter is selected to be much lower than the switching frequency, thus essentially eliminating the switching frequency ripple in the output voltage. The higher values of $\mathrm{L}_{2}$ and $\mathrm{C}_{2}$ assign the better output voltage and current but on the expense of the system time response. The parameters values of the designed system are given in Appendices.

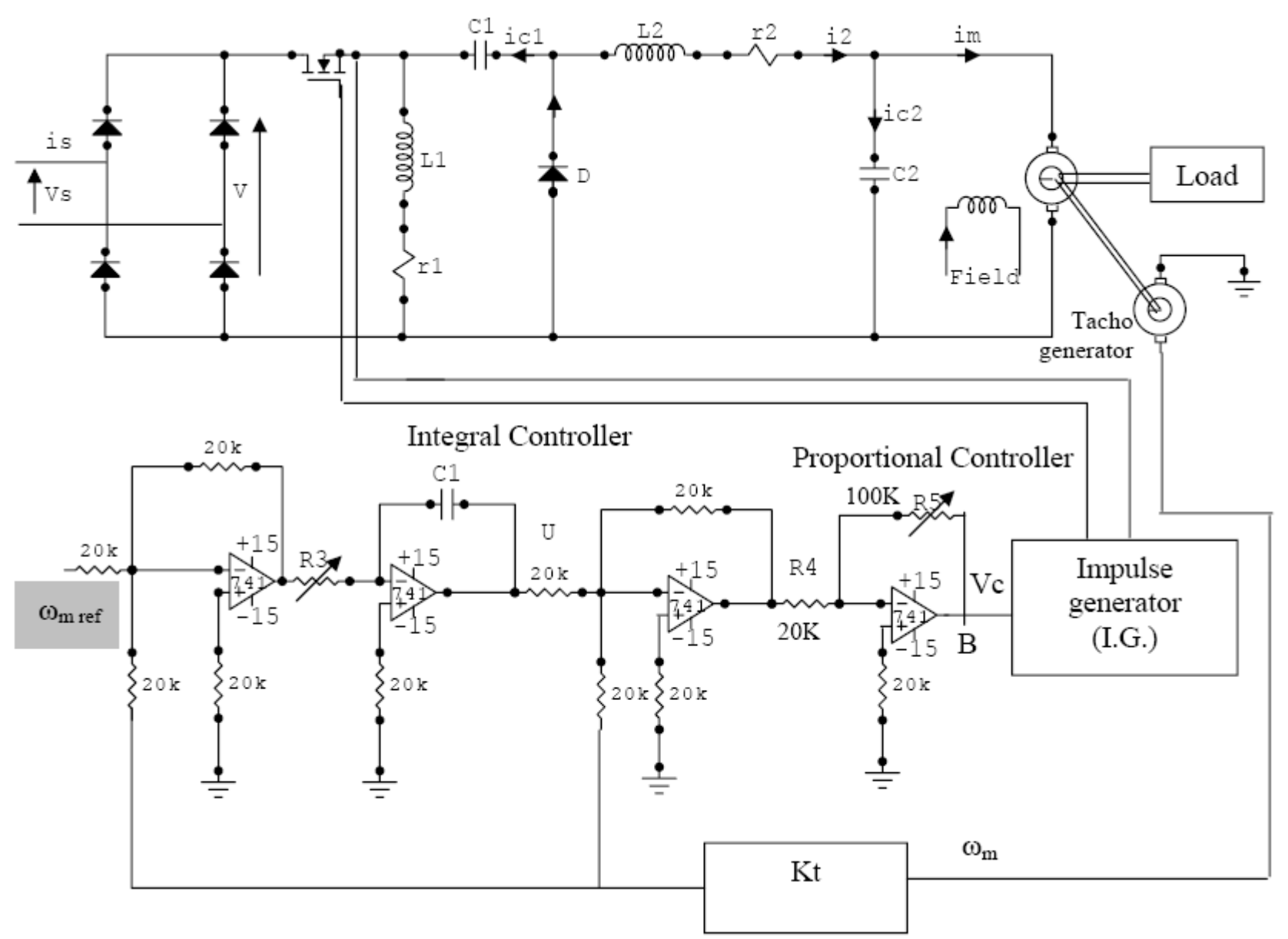

Figure 1. Schematic diagram of the experimental system 


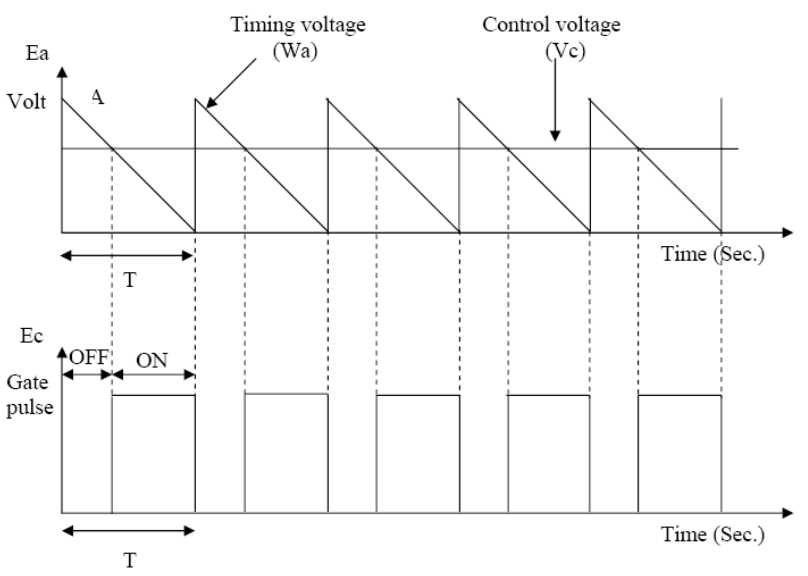

Figure 2. Output of the drive and control circuit

\section{SYSTEM MODELING AND MODES OF OPERATIONS:}

A step-up and down of the output voltage can be obtained by regulating the duty ratio, where:

Duty ratio $\mathrm{K}=\mathrm{T}_{\text {on }} / \mathrm{T}$

Where $T_{\text {on }}$ is the switch on time.

$\mathrm{T}$ is the switch (on + off) time.

The motor is separately excited DC motor. The load is separately excited DC generator. The switching frequency is given by:

$$
\mathrm{f}_{\mathrm{s}}=1 / \mathrm{T}
$$

The motor parameters are given in Appendix 3.

There are three modes of operation. Such modes of operation may be explained in the following sections.

\subsection{Mode (1)}

In this mode the MOSFET is on and the diode is off, while the MOSFET is conducting the line source supply energy to inductor $\mathrm{L}_{1}$. The energy available in inductor $\mathrm{L}_{2}$ comes from line source and capacitor $\mathrm{C}_{1}$. The currents $i_{L 1}$ and $i_{L 2}$ increase. Voltages $V_{m}$ and $e$ are considered constant and equal to load voltage. The differential equations describing this mode are:

$\frac{\mathrm{di}_{1}}{\mathrm{dt}}=\frac{\mathrm{v}-\mathrm{r}_{1} \mathrm{i}_{1}}{\mathrm{~L}_{1}}$

where: $\mathrm{v}=\mathrm{V}|\sin \omega \mathrm{t}|$

$$
\frac{\mathrm{de}}{\mathrm{dt}}=\frac{\mathrm{i}_{\mathrm{s}}-\mathrm{i}_{1}}{\mathrm{C}_{1}}
$$

$\frac{d i_{m}}{d t}=\frac{v_{m}-r_{m} i_{m}-k_{m} \omega_{m}}{L_{m}}$

$\frac{\mathrm{d} \omega_{\mathrm{m}}}{\mathrm{dt}}=\frac{\mathrm{K}_{\mathrm{m}} \mathrm{i}_{\mathrm{m}}-\mathrm{B} \omega_{\mathrm{m}}-\mathrm{T}_{\mathrm{L}}}{\mathrm{J}}$

$\frac{\mathrm{dv}_{\mathrm{m}}}{\mathrm{dt}}=\frac{\mathrm{i}_{2}-\mathrm{i}_{\mathrm{m}}}{\mathrm{C}_{2}}$ $\frac{\mathrm{di}_{2}}{\mathrm{dt}}=\frac{\mathrm{v}-\mathrm{v}_{\mathrm{m}}-\mathrm{i}_{2} \mathrm{r}_{2}+\mathrm{e}}{\mathrm{L}_{2}}$

$\mathrm{i}_{\mathrm{s}}=\mathrm{i}_{1}+\mathrm{i}_{2}$

$\mathrm{i}_{\mathrm{D}}=0$

\subsection{Mode (2)}

In this mode the MOSFET is off while the diode is on. The MOSFET is turned off and the diode starts to conduct, the energy from $\mathrm{L}_{1}$ and $\mathrm{L}_{2}$ is transferred to $\mathrm{C}_{1}$ and $\mathrm{C}_{2}$ respectively. In mode (2) there is no energy circulation in the line, which assures that there is no any harmonic distortion in the current. The differential equations describing this mode may be written as:

$\frac{\mathrm{di}_{1}}{\mathrm{dt}}=\frac{-\mathrm{i}_{1} \mathrm{r}_{1}+\mathrm{e}}{\mathrm{L}_{1}}$

$\frac{\mathrm{de}}{\mathrm{dt}}=\frac{-\mathrm{i}_{1}}{\mathrm{C}_{1}}$

$\frac{d i_{m}}{d t}=\frac{v_{m}-r_{m} i_{m}-k_{m} \omega_{m}}{L_{m}}$

$\frac{\mathrm{d} \omega_{\mathrm{m}}}{\mathrm{dt}}=\frac{\mathrm{K}_{\mathrm{m}} \mathrm{i}_{\mathrm{m}}-\mathrm{B} \omega_{\mathrm{m}}-\mathrm{T}_{\mathrm{L}}}{\mathrm{J}}$

$\frac{\mathrm{dv}_{\mathrm{m}}}{\mathrm{dt}}=\frac{\mathrm{i}_{2}-\mathrm{i}_{\mathrm{m}}}{\mathrm{C}_{2}}$

$\frac{\mathrm{di}_{2}}{\mathrm{dt}}=\frac{-\mathrm{i}_{2} \mathrm{r}_{2}+\mathrm{v}_{\mathrm{m}}}{\mathrm{L}_{2}}$

$\mathrm{i}_{\mathrm{s}}=0, \mathrm{i}_{\mathrm{D}}=\mathrm{i}_{1}+\mathrm{i}_{2}$

\subsection{Mode (3)}

In this mode both MOSEFT and the diode are off. When the current $i_{L 1}$ and $i_{L 2}$ become equal, the diode turns off and starts the mode (3). The voltage applied in the inductances $\mathrm{L}_{1}$ and $\mathrm{L}_{2}$ are zero and their currents are constant until MOSFET is able to conduct, restarting the operation cycle. The differential equations describing this mode are:

$$
\begin{aligned}
& \frac{\mathrm{di}_{\mathrm{m}}}{\mathrm{dt}}=\frac{\mathrm{v}_{\mathrm{m}}-\mathrm{r}_{\mathrm{m}} \mathrm{i}_{\mathrm{m}}-\mathrm{k}_{\mathrm{m}} \omega_{\mathrm{m}}}{\mathrm{L}_{\mathrm{m}}} \\
& \frac{\mathrm{d} \omega_{\mathrm{m}}}{\mathrm{dt}}=\frac{\mathrm{K}_{\mathrm{m}} \mathrm{i}_{\mathrm{m}}-\mathrm{B} \omega_{\mathrm{m}}-\mathrm{T}_{\mathrm{L}}}{\mathrm{J}} \\
& \frac{\mathrm{dv} \mathrm{m}}{\mathrm{dt}}=\frac{-\mathrm{i}_{\mathrm{m}}}{\mathrm{C}_{2}} \\
& \mathrm{i}_{\mathrm{s}}=0, \mathrm{i}_{\mathrm{D}}=0, \mathrm{i}_{1}=0
\end{aligned}
$$

\subsection{Modeling of the Drive Circuit}

The saw tooth carrier signal $\left(\mathrm{W}_{\mathrm{a}}\right)$ is given by the following equation: 
$\mathrm{Wa}=\mathrm{A}[1-\mathrm{X} / \mathrm{T}]$

Where: $T=1 / f_{s}, \quad f_{s}$ is the switching frequency,

$\mathrm{X}$ is the instant of the intersection in radians, and $\mathrm{A}$ is the peak value of the carrier voltage.

If the control voltage $\mathrm{V}_{\mathrm{c}}$ is greater than $\mathrm{W}_{\mathrm{a}}$ then the MOSFET is on, but if the $\mathrm{V}_{\mathrm{c}}$ is smaller than $\mathrm{W}_{\mathrm{a}}$ then the MOSFET is off.

\subsection{Controller Equations:}

The controller equations are given by:

$$
\begin{aligned}
& \tau(\mathrm{dU} / \mathrm{dt})=\omega_{\mathrm{mRef}}-\mathrm{K}_{\mathrm{t}} \omega_{\mathrm{m}} \\
& \mathrm{Vc}=\mathrm{K}_{1}\left(\mathrm{U}-\mathrm{K}_{\mathrm{t}} \omega_{\mathrm{m}}\right)
\end{aligned}
$$

Where $\mathrm{K}_{1}$ and $\tau_{1}$ are the IP speed controller parameters.

\section{STEADY STATE CHARACTERISTICS}

Figure (3) shows the effect of varying duty ratio on speed and power factor at 0.25 and 0.5 full-load conditions.
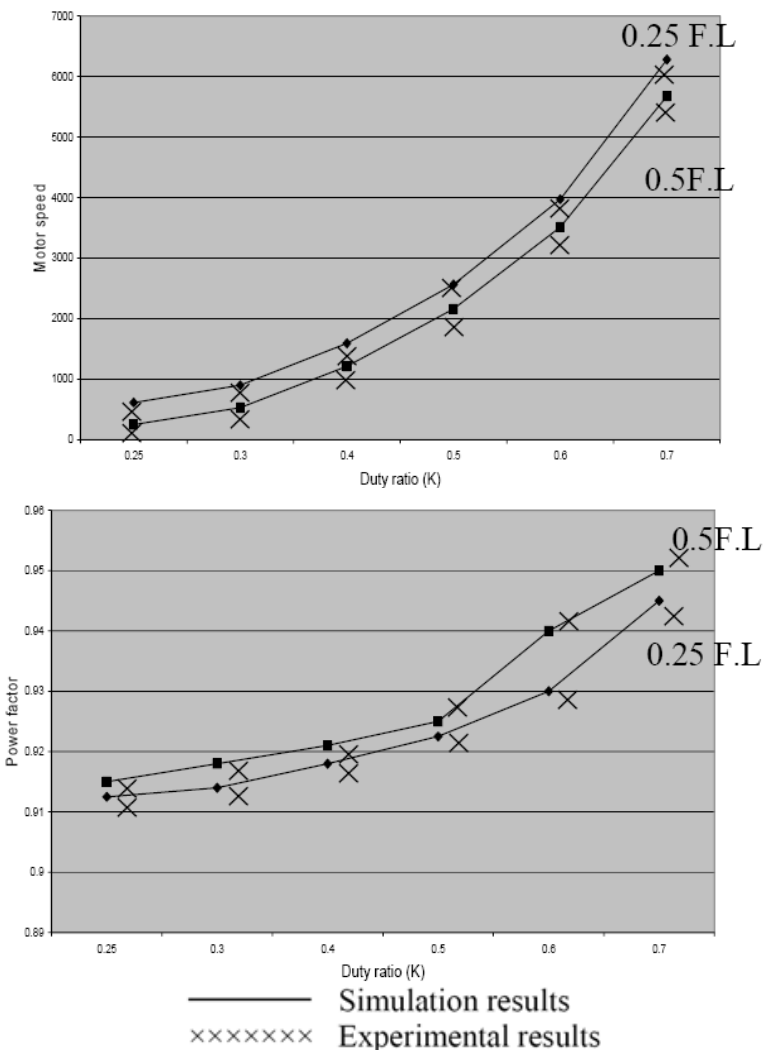

Figure (3) Effect of duty ratio on the steady-state characteristics

\section{CLOSED LOOP SPEED CONTROL OPERATION}

In reference [12-13], it is shown both theoretically and experimentally, that integral proportional controller (IP) offers good advantages over conventional (PI) controller. The transfer function can be obtained from the simulation results for different loads.
The system transfer function may take the following form:

$\frac{\omega_{\mathrm{m}}(\mathrm{s})}{\mathrm{V}_{\mathrm{c}}(\mathrm{s})}=\frac{\mathrm{K}_{\mathrm{s}}}{1+\tau_{\mathrm{s}} \mathrm{s}}$

Where $K_{\mathrm{s}}$ and $\tau_{\mathrm{s}}$ are shown in Appendix 3 .

The open loop transfer function of the system shown in figure (1) is given by:

$$
\frac{\omega_{\mathrm{m}}(\mathrm{s})}{\omega_{\text {mref }}(\mathrm{s})}=\frac{\mathrm{K}_{1} \mathrm{~K}_{\mathrm{s}} \mathrm{K}_{\mathrm{t}}}{\left(\tau_{1} \mathrm{~s}\right)\left(1+\tau_{\mathrm{s}} \mathrm{s}\right)}
$$

For the system to be stable, the cross-over frequency $\omega_{\text {co }}$ for a phase margin more than $45^{\circ}$ is found to be equal to the following equation:

$\omega_{\text {co }}=\mathrm{K}_{1} \mathrm{~K}_{\mathrm{s}} \mathrm{K}_{\mathrm{t}} / \tau_{1}$

This method of designing and calculating the speed controller parameters $\left(\mathrm{K}_{1}, \tau_{1}\right)$ has the advantage of being straight-forward, simple and accurate. The speed controller parameters are given in Appendix 3.

\subsection{Simulation and Experimental Results}

Figure (4) shows the variation of motor speed due to positive and negative change in load within $\pm 50 \%$ of the motor existing load. It is observed that the speed is returned to its initial value.

Figure (5) shows the positive and negative step change in reference voltage $\left[\omega_{\text {mref }}(s)\right]$ at half full load.

It is observed that the motor speed can follow the desired speed reference smoothly with a reasonable over shoot.

\section{6- CONCLUSIONS}

This paper has presented mathematical models by which the performance of a separately excited DC motor fed from AC- DC zeta converter may be successfully predicted.

The proposed control circuit for this system has been achieved nearly unity power factor. Moreover, the DC motor voltage and current were appeared to be ripple free and smooth.

The dynamic and steady-state behaviors were predicted using the proposed analysis. Further, the obtained experimental results may be used to determine the suitable IP speed controller's parameters for closed loop speed control. However, the best responses for load and speed reference disturbances could be obtained.

The speed controller's parameters were predicted for a constant speed operation when the load changes within $\pm 50 \%$ of the motor existing load. The motor speed can follow the desired speed reference smoothly and fast with reasonable overshoot.

A good agreement between the simulation and experimental results for open and closed loop systems was found. 

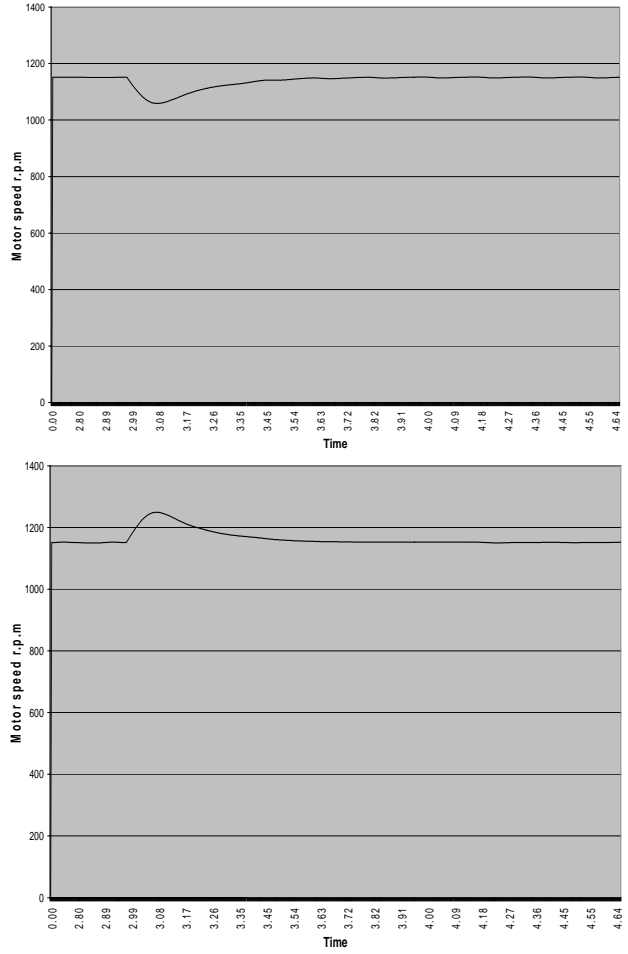

a) Simulation
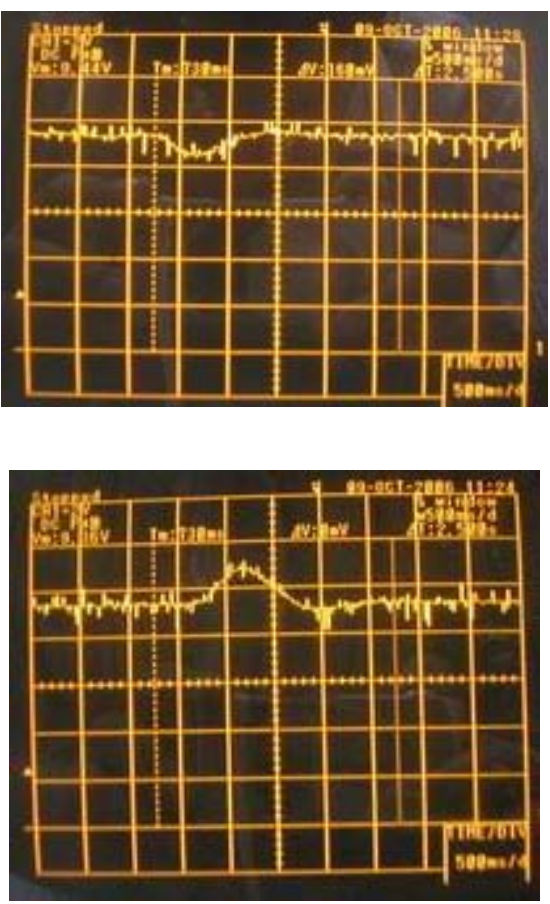

b) Experimental

Figure (4) Variation of speed due to positive and negative change in load torque Samples of the steady-state waveforms at 0.5 full load and $\mathrm{K}=0.5$
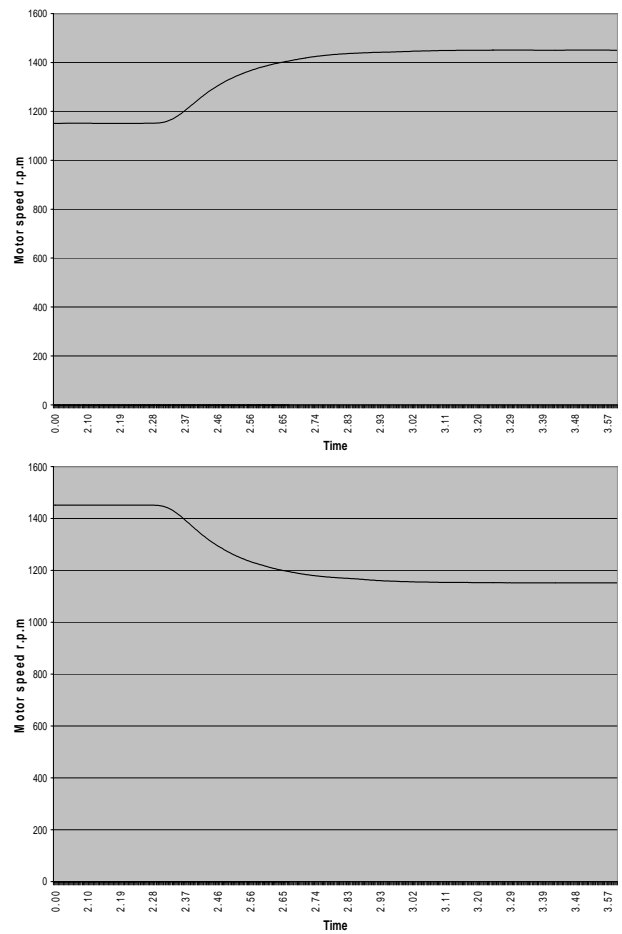

a) Simulation
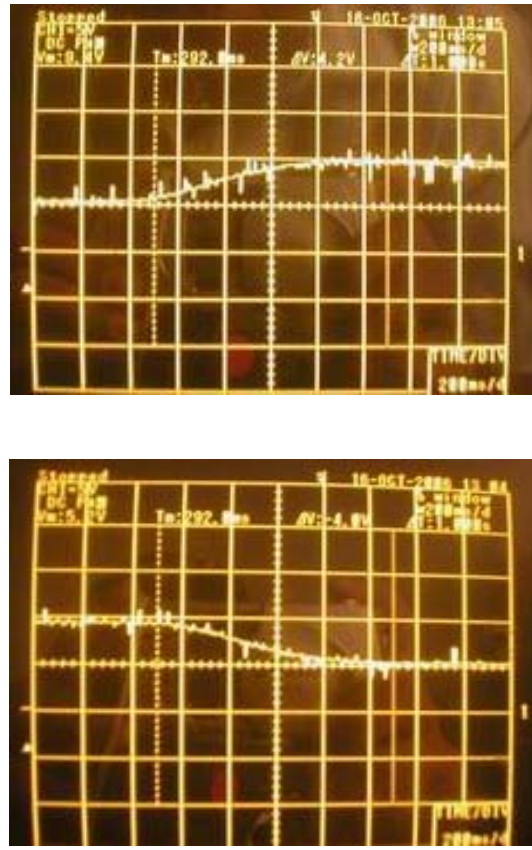

b) Experimental

Figure (5) Variation of speed due to positive and negative step change in reference voltage at half full load 


\section{REFERENCES}

[1] R. Itoh and K. Ishizaka," Single-Phase Sinusoidal Converter Using MOSFET'S", Proc. Inst. Elect. Eng. B. Elect. Power Appl., Vol. 136, Sept., pp. 237-242, 1989

[2] M. Kazerani, P.D Ziogas, and G. Joos, "A novel Active Current Waveshaping Technique for SolidState Input Power Factor Conditioners", IEEE Trans. Ind. Electron., Vol. 38, Feb. pp. 72-78, 1991

[3] S. Manias, "Novel Full Bridge Semicontrolled Switch Mode Rectifier", Proc. Inst. Elec. Eng. B. Elect. Power Appl., Vol. 138, Sept. pp 252-256, 1991

[4] A. R. Prasad, P.D. Ziogas, and S. Manias, "An Active Power Factor Correlation Technique for Three-Phase Diode Rectifiers", IEEE Trans. Power Electron, Vol. 6, Jan. pp. 83-92, 1991

[5] J.T. boys and A. W. Green, "Current-Force Single-Phase Reversible Rectifier", Proc. Inst. Elec. Eng. B. Elect. Power Appl., Vol. 136, Sept. pp 205-211, 1989.

[6] R. Itoh and K. Ishizaka, "Single-Phase Sinusoidal Rectifier with Step-Up/down Characteristics" , Proc. Inst. Elect. Eng. B. Elect. Power Appl., Vol. 138, Nov., pp 338-344, 1991

[7] A.E Lashine and F.A Saafan, "Analog Control of Cuk Converter With High Quality Performance", Engineering Research Bulletin, Menoufiya Univ., Faculty of Eng., Vol. 19, No 1, pp. 17-33, 1996

[8] A. E Emanuel and K.K Sen, "Steady-State Performance of the DC Motor Supplied From Single-Phase Rectifier With Step-Up Converter A Unity Power Factor Converter", IEEE Trans. On Energy conversion, Vol. 3, No. 1, March, pp. 172178,1988

[9] H. Oishi, Hokada, K. Ishizaka and R. Itoh, "SepicDerived Three-Phase Sinusoidal Rectifier Operation in Discontinuous Current Conduction Mode", IEE Proc- Electr. Power Appl., Vol. 142, No. 4, July 1995, pp.239-245

[10] M. E. El-Shebiny, " Performance Characteristics of a Flyback Converter Fed DC motor",
Engineering Research Journal, Volume 25, No. 1, January 2002, pp.1-15.

[11] D. C. Martins and M. M. Casaro, "Isolated Three-Phase Rectifier with High Power Factor Using the Zeta Converter in Continuous Conduction Mode", IEEE Trans. on Circuit and Systems- I: Fundamental Theory and Applications Vol. 48, No. 1, January 2001, pp. 74-80

[12] El-Tobshy, A. M., Mahfouz, A. A., Ibrahim, M. S., "Integral-Proportional (I-P) Controller for DC Motor Drives", Proceedings of Al-Azhar Engineering Fourth International Conference, Dec. 16-9, 1995, pp. 272-283

[13] S. S. Shokralla, "A Simplified Approach for Closed Loop Speed Control of a DC Motor Using AC- to -DC Converter", Alexandria Engineering Journal, Vol. 36, No. 2, March 1997, pp. B29-B41

\section{APPENDICES}

\section{Appendix (1)}

The parameters of the designed system are as follows: $\mathrm{V}_{\mathrm{s}}=50$ volt $\quad \mathrm{L}_{1}=30 \mathrm{mH} \quad \mathrm{r}_{1}=1.5 \mathrm{ohm}$ $\mathrm{C}_{1}=15 \mu \mathrm{f} \quad \mathrm{L}_{2}=30 \mathrm{mH} \quad \mathrm{r}_{2}=1.5 \mathrm{ohm}$ $\mathrm{C}_{2}=2200 \mu \mathrm{f} \quad \mathrm{A}=12$ volt

\section{Appendix (2)}

The values of IP speed controller parameters are as follows:

$\begin{array}{llllll}\mathrm{R}_{3}=40 & \mathrm{~K} \Omega & \mathrm{R}_{4}=30 & \mathrm{~K} \Omega & \mathrm{R}_{5}=30 & \mathrm{~K} \Omega\end{array}$

$\mathrm{C}_{3}=3.3 \mu \mathrm{f} \quad \omega_{\text {mref }}=2.89$ volt

$\mathrm{K}_{\mathrm{t}}=0.019 \mathrm{volt} / \mathrm{rad} / \mathrm{sec} \quad \mathrm{K}_{\mathrm{s}}=10$

$\mathrm{K}_{1}=1 \quad \tau_{1}=0.14 \mathrm{sec} \quad \tau_{\mathrm{s}}=0.09 \mathrm{sec}$

\section{Appendix (3)}

The test motor is a separately excited DC motor, 50 volt , 55 watt, 1 ampere, $3000 \mathrm{rpm}$ having the following measured parameters:

$\mathrm{R}_{\mathrm{a}}=10.5 \mathrm{ohm} \quad \mathrm{L}_{\mathrm{m}}=0.06 \mathrm{H} \quad \mathrm{R}_{\mathrm{f}}=550 \mathrm{ohm}$ $\mathrm{B}=0.0001 \mathrm{~N} . \mathrm{m} . /(\mathrm{rad} / \mathrm{sec})$

$\mathrm{K}_{\mathrm{m}}=0.127 \mathrm{Volt} /(\mathrm{rad} / \mathrm{sec})$

$\mathrm{J}=0.0012 \mathrm{~kg} \cdot \mathrm{m}^{2}$ 